justifiable inference. But how, or precisely why, they occur is a matter which demands a more intensive study than it has yet received.

\section{Mexican Archæological Exhibits at Chicago}

AN extensive selection of the remarkable series of relics found in the tombs of Monte Alban in the state of Oaxaca, Mexico, is being shown at the Century of Progress Exposition, Chicago. It includes ornaments in gold, jade, pearl, and other precious, or semiprecious, material. The exhibit is in charge of Señor Alfonso Caso, the excavator and director of the expedition by which the tombs were first discovered. One of the most remarkable exhibits, recently described in a communication from Science Service, Washington, is a human skull covered with a mosaic of small flat pieces of turquoise and fitted with eyes of pearl shell and a nose of flint. The skull is a representation of the god Tezcatlipoca, the god of the sky and Nature. Only one other skull treated in this way is known. This is now in the British Museum. The exhibits also include a number of objects which are considered to point to a knowledge in ancient Mexico of the art of the turner. A chalice of rockcrystal and several pairs of large spool-shaped earpendants, of the same material, are so accurate in outline as to suggest that they could have been cut in this hard material only with a mechanical aid such as the lathe.

\section{North American Archæology}

MUSEUM handbooks not infrequently appeal to a wider public than that to which the collections are accessible. Especially is this evident when, as in a guide to exhibits illustrating the archæology of North America recently issued by the Field Museum of Natural History, Chicago, the subject is treated on broad lines, rather than the exhibits described in detail. In Hall B of the Field Museum series of exhibits have been arranged to illustrate the archæology of each of the cultural areas, into which anthropologists have divided the continent, with the exception of the Plains area, from which material is scant, and the south-western States which are represented in another hall. The author of the guide, Mr. P. B. Martin, an assistant curator of the Museum, has given his attention mainly to summarising on broad lines the principal conclusions of American archæological studies, as they now stand, in relation to the crucial problems of the early history of man and his culture on the American continent. Thus in addition to a description of artefacts in stone, copper, bone and shell and the pottery, as well as the methods of their manufacture, he discusses the origin of the Indian, the antiquity of man in America, the culture of the mound-builders, and the classification of culture areas. It is interesting to note that in the formation of these collections, the aim of their assemblage and arrangement has been, not the exhibition of specimens remarkable for their rarity or exceptional character, but the illustration of essential features in each type of culture. As an introduction to the broad facts of American archæology this handbook has much to commend it.

\section{Modern Whaling in the Antarctic}

Capt. Harold Keith Salvesen's lecture on modern whaling in the antarctic, given before the Royal Society of Arts on February 15, is now printed in the Journal of that Society, vol. 81, 1933. Nobody is better qualified to give information on this subject, for his family has been closely connected with whaling since the introduction of the modern whaling gun which completely revolutionised the industry. Exactly twenty-one years ago, his father lectured to the same Society on modern whaling, and since then many changes have taken place, rather of degree than of kind, with one important exception, the adoption of ice-fishing, and the present lecture deals almost entirely with ice-fishing. In 1930-31, the antarctic production was forty-seven times that of the combined total of the rest of the world, the increase in the production being due exclusively to the icefishing of 41 floating factories and 201 catches. It is satisfactory to know that this ice-fishing caused a great reduction in tropical fishing and also in the South Georgia area, where the percentage of immature whales is very high, the animals in the ice regions being fat and full of oil. Capt. Salvesen is emphatic in his opinion that there is no need to fear the extinction through whaling of any species of whale in the antarctic, although there is much to fear from over fishing unless there are proper and sufficient restrictions. Future agreements continuing to regulate the number of whales killed and especially to enforce the least amount of waste should do much to minimise the dangers of over-fishing.

\section{Ice-cooled homes}

According to Science Service of July 7, research chemists of the University of Illinois under the direction of Prof. Dana Burks have made progress in reducing the cost of manufacturing ice. If the air in small houses is to be kept cool and free from humidity, ice or a mechanical refrigerator must be used. Both methods are in common use and both have advantages. If ice is to be widely used for aircooling, it will be necessary to sell it in fairly large quantities at not more than about 15 shillings a ton. Prof. Burks has been successful in showing how the distillation process sometimes used can be made unnecessary. Owing to the presence of salts onethird of the ice-manufacturing plants in the United States have to distil the water they use. A special ice can is employed which allows air to pass across the surface of the ice crystals as they grow. This agitation prevents the salts from concentrating and a clear, strong ice block is produced. The method has been tested with all kinds of synthetic waters without distillation, with satisfactory results. The time required for freezing the ice has also been shortened from 47 to 24 hours. This was effected by using special small cans and by lowering the temperature of the brine used in the freezing. The report on the experi. ments says that a saving of about thirty per cent in the cost of manufacture can be effected in this way. It has been demonstrated that it is possible to make 